Inovação curricular: contribuições finlandesas para estruturação de programas brasileiros de formação continuada de professores. Revista Ensaios, vol. 15, jul-dez de 2019.

\title{
Inovação curricular: contribuições finlandesas para estruturação de programas brasileiros de formação continuada de professores.
}

\author{
Azenaide Abreu Soares Vieira ${ }^{1}$ \\ Conceição de Maria Cardoso Costa² \\ Essi Ryymin ${ }^{3}$
}

\begin{abstract}
Resumo: O presente artigo tem por objetivo apresentar o currículo de dois programas de formação de professores que podem ter o potencial de atender às demandas de formação continuada de professores frente aos novos desafios educacionais. O primeiro é o Programa VET III - Teacher for the Future, estruturado por educadores finlandeses, e o segundo é o curso MAES Metodologias Ativas de Aprendizagem para o Estudante do Século XXI, estruturado por educadores brasileiros egressos do Programa VET. Trata-se de uma pesquisa qualitativa, descritiva e explicativa. Os referenciais teóricometodológicos pautam-se na pesquisa aplicada, com características da etnografia. Dentro dos aspectos modificados pelo MAES destacam-se: o público-alvo, acréscimo de rubricas e narrativas como instrumento de avaliação, concomitância da formação com a atuação e a individualização do currículo.
\end{abstract}

Palavras-chave: Formação de Professores; Currículo; Metodologias Ativas.

Curriculum innovation: finnish contributions to brazilian program structure for continuing teacher training.

Abstract: This article aims to present the curriculum of two teacher education programs that may have the potential to meet the demands of continuing teacher education to face the new educational challenges. The first is the VET III Program - Teacher for the Future, structured by Finnish educators, and the second is the MAES - Active Learning Methodologies for the Student of the 21st Century, structured by Brazilian educators graduated from VET III Program. The research is characterized as qualitative, descriptive and explanatory. The theoretical-methodological references are based on applied research, with ethnography characteristics. Within the aspects modified by MAES we can highlight: the target audience, addition of rubrics and narratives as tools for valuation, in service training, and the individualization of the curriculum.

Keywords: Teacher training; Curriculum; Active Methodologies.

\footnotetext{
${ }^{1}$ Estágio pós-doutoral na HAMK School of Professional Teacher Education, Finlândia. Pós-doutora na Universidade Federal de Minas Gerais (UFMG). Doutora em Estudos Linguísticos pela Universidade do Estado de São Paulo (UNESP). Mestre em Educação Universidade Católica Dom Bosco (UCDB). Licenciada em Letras Português/Inglês Faculdades Integradas de Fátima do Sul (FIFASUL). Professora e Pesquisadora do Instituto Federal de Mato Grosso do Sul (IFMS). Brasil, Nova Adradina, Mato Grosso do Sul. azenaide.vieira@ifms.edu.br.

2 Graduada em Engenharia Civil pela Universidade Federal da Paraíba (UFPB). Especialização em Engenharia de Segurança do Trabalho, pela Universidade Federal da Paraíba (UFPB), Mestrado em Engenharia Civil pela Universidade Federal da Paraíba (UFPB) e Doutorado em Geotecnia pela Universidade de Brasília (Unb). Professora do Instituto Federal de Educação, Ciência e Tecnologia de Brasília (IFB). Brasil, Brasília, Distrito Federal. conceicao.costa@ifb.edu.br.

3 Doutora em Educação e professora da Häme University of Applied Sciences (HAMK). Filândia. essi.ryymin@hamk.fi.
} 
Inovação curricular: contribuições finlandesas para estruturação de programas brasileiros de formação continuada de professores. Revista Ensaios, vol. 15, jul-dez de 2019.

No centro da discussão temos dois programas de Formação de Professores sob o olhar atento e criterioso da análise científica: um programa internacional, resultado da parceria Brasil-Finlândia - VET III Teacher for the Future -, apreendido a partir do ponto de vista do estudante provocado pelas escolhas e enfoques de educadores finlandeses; outro, idealizado e implementado por formadores brasileiros, o curso MAES Metodologias Ativas para o Estudante do Século XXI, analisado pelo prisma de quem cria e, a partir do exercício de reflexão-na-ação e reflexão-sobre-a-ação (SCHÖN, 2000), descobre o objeto de sua criação. É esse objeto, o currículo do curso MAES, que procuraremos desvendar ao longo do texto, no intuito de compreender e fazer compreensível a trama linguística formada no ato de descrever a ação vivida pelos atores (SILVA, 2017).

As teorias de currículo que sustentam a investigação são multifacetadas, às vezes até impossíveis de serem descritas com precisão. Como indivíduos que criam e, constantemente, buscam clarear o objeto criado, partimos da perspectiva sobre currículo trazida por Silva (2017) para nortear a pesquisa. No mapa dos estudos sobre currículo apresentado por Silva (2017) encontramos base para descrever a trajetória que percorremos a partir do objeto criado ao longo do caminho, uma vez que "ao descrever um objeto, a teoria, de certo modo, inventa-o" (SILVA, 2017, p. 11). Assim como o autor, compreendemos currículo como a produção do discurso ou texto e como tal, ao relatar o percurso do Programa VET III e do curso MAES, somos direcionados por inquietações como: quais os currículos prescritos do VET III e do MAES? De que forma o MAES ressignifica o VET III para atender ao seu contexto de implementação?

A pesquisa se justifica por trazer contribuições relevantes à área educacional no que concerne a repensar currículos de programas de formação continuada de professores. No cenário educacional brasileiro atual, provocado pela publicação da Base Nacional Comum Curricular (BNCC) do ensino fundamental da educação básica e pela sanção da lei $N^{\circ} 13.415 / 2017$ que preconiza a reforma do ensino médio, a análise de currículos diferenciados de formação de professores pode provocar ressignificações de programas que mantêm uma lógica de sociedade de séculos passados. Assim, temos a expectativa de que o presente texto fomente a construção de novos programas de formação de professores alinhados às exigências sociais de sua época. 
Inovação curricular: contribuições finlandesas para estruturação de programas brasileiros de formação continuada de professores. Revista Ensaios, vol. 15, jul-dez de 2019.

\section{1) Pressupostos teórico-metodológicos:}

Para produção de conhecimento científico sobre currículos implementados na Finlândia e no Brasil com propósito de formar professores brasileiros para atuação no cenário contemporâneo, partimos do paradigma da pesquisa qualitativa, descritiva e explicativa, alicerçada nos pressupostos teórico-metodológicos da pesquisa aplicada, de caráter intervencionista.

À luz da teoria de desenvolvimento humano trazida por Vygotsky (1896 a 1934), consideramos que ao produzir um conhecimento a partir da pesquisa qualitativa estamos assumindo o princípio de que o conhecimento é resultado da inter-relação de pessoas, compreendendo "a aprendizagem como processo social compartilhado e gerador de desenvolvimento" (FREITAS, 2002, p. 25). Assim como Freitas (2002), consideramos que a abordagem de pesquisa qualitativa permite transformar por meio da descrição e explicação do objeto apreendido, no movimento de refletir, em um processo dialógico mediado por signos e ferramentas tecnológicas produzidas pela sociedade (VYGOTSKY, 1984).

A pesquisa qualitativa nos orienta na compreensão dos currículos experienciados em sua "complexidade e em seu acontecer histórico" (FREITAS, 2002, p. 27). Pautados nas ideias da autora, não criamos artificialmente uma situação curricular para ser pesquisada, o que fazemos é ir "ao encontro da situação no seu acontecer, no seu processo de desenvolvimento", para materializá-la com rigor científico. Na condição de sujeito e objeto de nossa pesquisa, dotados de conhecimentos parciais e visão limitada do todo estudado, buscamos o "aprofundamento da compreensão" (SILVEIRA \& CÓRDOVA, 2009, p. 31) da organização dos currículos reais de formação de educadores brasileiros.

Como objetivamos "gerar conhecimentos para aplicação prática, dirigidos à solução de problemas específicos" (SILVEIRA \& CÓRDOVA, 2009, p. 35) referentes à reestruturação de currículos de programas de formação de professores para atender demandas locais e globais, a pesquisa configura-se como aplicada. 
Inovação curricular: contribuições finlandesas para estruturação de programas brasileiros de formação continuada de professores. Revista Ensaios, vol. 15, jul-dez de 2019.

Quanto aos procedimentos metodológicos, a pesquisa tem um cunho etnográfico, pois adotamos uma postura de observadores-participantes ao experienciar tanto o currículo coordenado pelos educadores finlandeses quanto o currículo coordenado por nós, em contexto de formação continuada de professores no Brasil. A etnografia se materializa, também, pela ênfase que damos ao processo, trazendo nossa “visão sobre as experiências”. (SILVEIRA \& CÓRDOVA, 2009, p. 41).

No intuito de tornar evidente e analisar a influência da aprendizagem construída pelos educadores brasileiros a partir da realização do Programa VET III Teachers for the Future, realizado na Finlândia em 2016, apresentamos a estrutura do currículo do VET, para então analisar as similaridades e ressignificações desse curso com o Curso MAES.

\section{2) O programa VET professores para o futuro:}

O VET - Vocational Educational and Training - Professores para o Futuro é um programa de certificação profissional para professores que atuam nos Institutos Federais de Educação, Ciência e Tecnologia no Brasil. É uma proposta das universidades de Ciências Aplicadas HAMK e TAMK, construída em parceria com a Secretaria de Educação Profissional e Tecnológica (SETEC) e o Conselho Nacional de Desenvolvimento Científico e Tecnológico (CNPq), objetivando promover aperfeiçoamento pedagógico de docentes brasileiros da Rede Federal de Educação Profissional, Científica e Tecnológica (RFEPCT). Envolve atividades de pesquisa aplicada, inovação pedagógica e educação profissional.

Nas três edições do Programa VET (doravante VET I, II e III) participaram da capacitação cento e seis (106) professores, no período de 2014-2016. Este programa finlandês foi estruturado para atender às necessidades de formação de professores dos Institutos Federais, conforme necessidades apresentadas pelo governo brasileiro. $\mathrm{O}$ propósito da Rede Federal de Educação Profissional, Científica e Tecnológica, ao buscar parceria com universidades finlandesas, foi responder às demandas social e econômica das regiões brasileiras, mediante pesquisa aplicada para impulsionar inovações e desenvolvimento local, assim como, criar redes entre diferentes níveis da 
Inovação curricular: contribuições finlandesas para estruturação de programas brasileiros de formação continuada de professores. Revista Ensaios, vol. 15, jul-dez de 2019.

educação profissional. O curso foi destinado a professores com diferentes formações iniciais que desejavam aprender como combinar teoria e prática pedagógicas aos seus campos de atuação profissional.

O currículo do programa VET foi estruturado por competência e possui uma natureza transdisciplinar, organizado por eixos temáticos. Contava com trinta (30) créditos e a duração varia de sete (7) a nove (9) meses. O estudo no programa foi dividido em duas (2) partes, incluindo seções de estudo na Finlândia e no Brasil. Na primeira parte, de três (3) a cinco (5) meses, os professores brasileiros estudaram em ambientes finlandeses de aprendizagem em Universidades de Ciências Aplicadas localizadas nas cidades de Hämeenlinna (HAMK) e Tampere (TAMK). Depois deste período, eles retornaram ao trabalho, espaços de aprendizagem no Brasil, para implementação e avaliação do desenvolvimento pedagógico e científico por quatro (4) ou cinco (5) meses. Durante a fase de desenvolvimento do programa no Brasil, os professores receberam orientações online de professores finlandeses, que atuaram como tutores.

O objetivo do Programa VET é, colaborativamente, encorajar os participantes a repensar o desenho educacional e os ambientes de aprendizagem que melhor respondam a realidades regionais e desafios futuros. Os principais conteúdos do programa incluem aprendizagem ativa e centrada no estudante, modelos para mudança educacional, construção de comunidade de aprendizagem e utilização de ferramentas digitais para educação (RYYMIN et al., 2016). Há muitos desafios globais similares para formação de professor; professores precisam ser, por exemplo, aprendizes contínuos, co-criadores e "agentes de mudança" de nova pedagogia em seus ambientes de trabalho e aprendizagem. Com o objetivo de atender necessidades profissionais globais, a integração de conhecimentos teórico, prático, autorregulado e sociocultural do professor é essencial (TYNHÄLÄ et al., 2014).

Portanto, o programa VET busca combinar ações de formação de professores, pesquisa aplicada e ensino-aprendizagem a partir do desenvolvimento de projetos (Project Based Learning - PBL), sem perder de vista a aprendizagem para e no mundo do trabalho. Os participantes do programa VET são de áreas educacionais distintas, por 
Inovação curricular: contribuições finlandesas para estruturação de programas brasileiros de formação continuada de professores. Revista Ensaios, vol. 15, jul-dez de 2019.

exemplo biotecnologia, engenharias, agronomia, ciência da computação, química, matemática, linguística, educação e administração de empresa. Os professores trabalham em Institutos Federais no Brasil, em cursos profissionalizantes que vão do nível médio à pós-graduação.

Na Universidade de Ciências Aplicadas Häme (HAMK), a pesquisa é um elemento fundamental para definir o desenho e o desenvolvimento de programas de formação de professores. No VET Professores para o Futuro, a pesquisa intervencionista foi baseada em desenho instrucional (FISHMAN et. al., 2013) é aplicada como um quadro de referência para investigação e desenvolvimento da formação de professores brasileiros. $\mathrm{O}$ estabelecimento de redes de pesquisa entre educadores brasileiros e finlandeses é uma meta de longo prazo da cooperação para os finlandeses. Na sequência, detalhamos o programa VET III, edição em que os autores participaram.

\section{3) O programa de formação de professores para o futuro VET III.}

O Programa VET III Professores para o Futuro implementado em 2016 foi organizado em duas fases, sendo uma dedicada ao período de estudos na Finlândia, incluindo experiências práticas e teóricas, e a segunda fase consistiu na aplicação prática das metodologias aprendidas com educadores finlandeses nos contextos locais dos professores-aprendizes. Em colaboração com colegas, cada participante construiu e desenvolveu um projeto de intervenção na prática pedagógica (PASSOS, VIEIRA \& COSTA, 2018), sob tutela de educadores finlandeses. Os resultados do trabalho desenvolvido no Brasil foram apresentados em seminário final, acontecido em novembro de 2016, em Maceió, Brasil. 
Inovação curricular: contribuições finlandesas para estruturação de programas brasileiros de formação continuada de professores. Revista Ensaios, vol. 15, jul-dez de 2019.

O Programa VET III foi estruturado com base em três (3) eixos temáticos principais, sendo: 1. Sociedade e sistema educacional Finlandês; 2. Processo de ensino e aprendizagem; 3. Currículo baseado em competências e Cooperação com empresas. Esses eixos foram abordados conforme os princípios da aprendizagem baseada em projetos (PBL, Project Based Learning em inglês) e pela aprendizagem em ambientes digitais (E-learning) para o século XXI. A Figura 1 resume a proposta conforme apresentada pelos educadores finlandeses da HAMK.

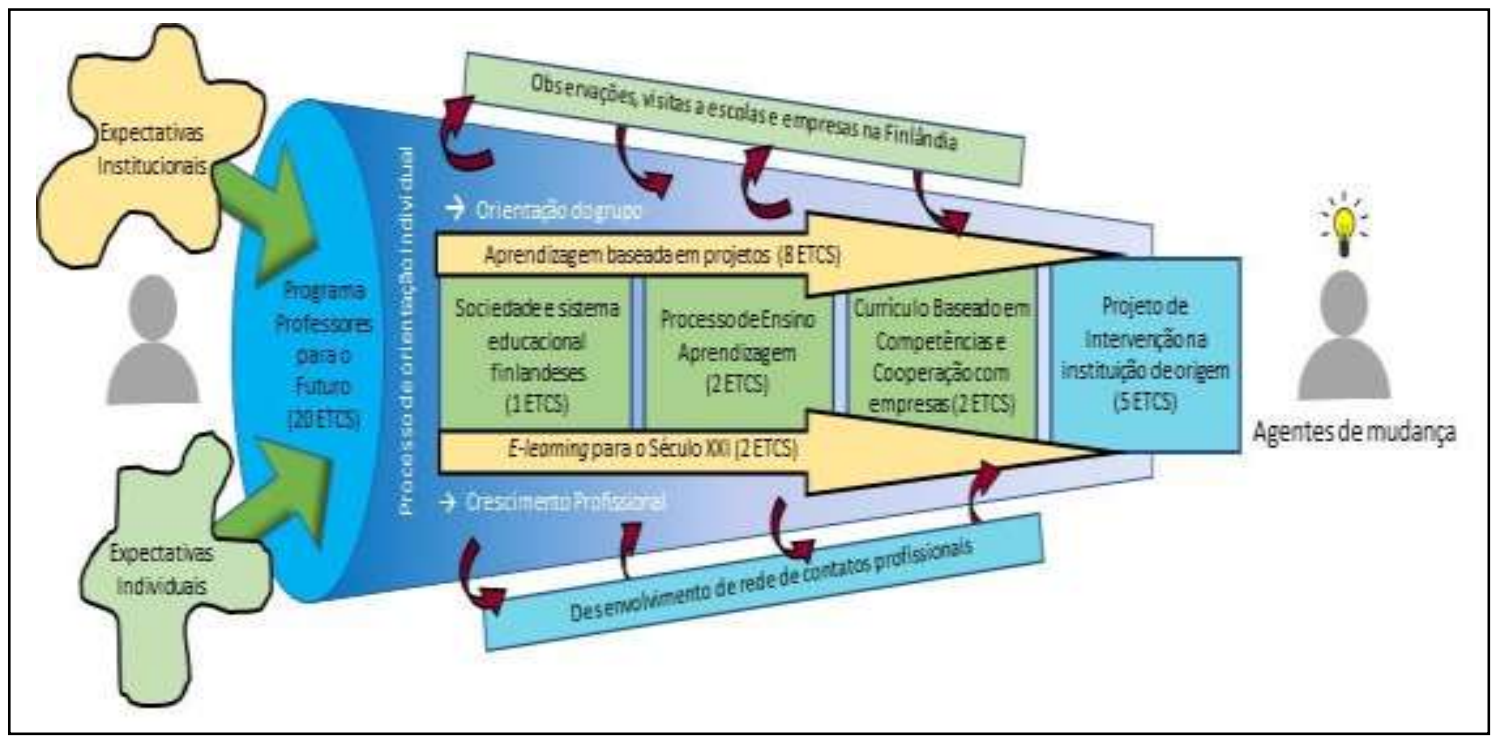

Figura 1: Proposta do Programa VET III Professores para o Futuro. Fonte: Joyce, B., Laurikainen, M., Kunnari, I., Ryymin, E. \& Viskari (2014-2016). Tradução dos autores.

Como observado na Figura 1, o programa foi desenhado e executado a partir do alinhamento entre as expectativas institucionais, tanto das universidades finlandesas como da Secretaria de Educação Profissional (SETEC/MEC), e individuais dos sujeitos responsáveis em coordenar o currículo do curso.

Por currículo, convém esclarecer que o compreendemos como "lugar, espaço, território, trajetória, viagem, percurso. O currículo é autobiografia, nossa vida, curriculum vitae: no currículo se forja nossa identidade. O currículo é texto, discurso, documento. O currículo é documento de identidade" (SILVA, 2017, p. 150).

Deste alinhamento, o currículo se desenvolveu a partir de eixos temáticos e não de disciplinas, observando-se a inexistência de hierarquias entre os eixos e discussões que aconteciam de forma paralela e integrada. O Programa VET III Teacher for the 
Inovação curricular: contribuições finlandesas para estruturação de programas brasileiros de formação continuada de professores. Revista Ensaios, vol. 15, jul-dez de 2019.

Future foi desenvolvido com base no desenvolvimento de competências pedagógicas, que tomam como ponto de partida as expectativas individuais e institucionais dos professores selecionados, utilizando a aprendizagem baseada em projetos e o uso de tecnologias digitais como alicerce para a discussão promovida pelos eixos. Cabe destacar que o conceito de competência que embasa a construção do currículo do VET é a combinação de conhecimento, prática e atitude, sendo que conhecimento consiste na aprendizagem teórica, a prática pauta-se na aprendizagem construída pelo ato de fazer learning by doing -, e atitude é proveniente da capacidade do professor em autorregular seu processo e desenvolver conhecimento sociocultural.

O primeiro momento, bastante desafiador para a maioria dos professores, foi refletir sobre as trajetórias profissionais, identificando e refletindo sobre objetivos individuais e metas durante a formação. Mesmo antes de chegar à Finlândia, os participantes responderam a um questionário que provocavam essas reflexões, apontando algo diferente de outras capacitações: uma preocupação com expectativas individuais e conhecimentos prévios.

Chegando à Finlândia, a primeira semana foi de muitas descobertas. Questões culturais foram apresentadas e vivenciadas, causando, num primeiro momento, incredulidade, resistência, estranhamento. Foram momentos de encontros com outras realidades, crenças, valores, não apenas relacionados à cultura Finlandesa, mas também e, principalmente, com os demais professores, vindos de diferentes regiões do Brasil, com expectativas e experiências diferenciadas. Nesta fase, os professores participaram de uma entrevista, que juntamente com as informações do questionário encaminhado anteriormente, serviu de base para a escolha das “famílias", grupos de estudos, trabalhos e discussões colaborativas. Foi preciso aprender a caminhar juntos, entender as diferenças individuais, compreender os estágios de cooperação e colaboração, aspectos comuns nos sistemas educacionais finlandeses e tão difíceis na realidade brasileira. Uma percepção inicial foi a certeza de que o caminho seria diferente. Era preciso reaprender a reconstruir. Os objetivos de aprendizagem individuais e do grupo precisavam estar claros. 
Inovação curricular: contribuições finlandesas para estruturação de programas brasileiros de formação continuada de professores. Revista Ensaios, vol. 15, jul-dez de 2019.

O foco era no processo, no percurso, no caminhar. Na primeira semana fomos desafiados a refletir sobre o currículo baseado em competência, compreender conceitos, sem nenhuma exposição prévia ao eixo temático "Currículo baseado em competências". O percurso era baseado em pesquisas, reflexões e compartilhamento de ideias. Muitas discussões em grupo, muitas incertezas e a sensação de que não sabíamos onde iríamos chegar. Ao mesmo tempo tentávamos entender que para os finlandeses "menos é mais", "aprende-se fazendo", "o estudante é o centro da aprendizagem".

Para isso, o currículo prescrito do VET III trouxe competências e objetivos de aprendizagem previamente delineados. Na sequência apresentamos os objetivos de aprendizagem pretendidos pelos educadores finlandeses responsáveis pelo VET III Professores para o Futuro, vinculados aos seus respectivos eixos temáticos:

Quadro 1: eixos temáticos e objetivos de aprendizagem pretendidos no VET III. Fonte: apresentação do programa VET III. Tradução dos autores.

\begin{tabular}{|c|}
\hline Processos de ensino e aprendizagem \\
\hline $\begin{array}{l}\text { Descrever como as atuais teorias de aprendizagem centrada no estudante impactam na estrutura, } \\
\text { implementação e avaliação de processos de aprendizagem (ex. individualização) }\end{array}$ \\
\hline $\begin{array}{l}\text { Demonstrar vários métodos colaborativos de ensino, orientação e facilitação de aprendizagem (ex. e- } \\
\text { learning) }\end{array}$ \\
\hline Avaliar e justificar escolhas pedagógicas como facilitadoras de aprendizagem de diversos estudantes. \\
\hline $\begin{array}{l}\text { Reconhecer e comparar culturas de trabalho e aprendizagem em suas instituições educacionais e } \\
\text { analisar como essas culturas afetam o ensino e a aprendizagem. }\end{array}$ \\
\hline E-learning para o século XXI \\
\hline $\begin{array}{l}\text { Utilizar mídia social e outras ferramentas online em seu processo de aprendizagem e para construção } \\
\text { de conhecimento colaborativo. }\end{array}$ \\
\hline $\begin{array}{l}\text { Justificar porque alfabetização e competência digital são necessárias como aprendizagem ao longo da } \\
\text { vida em um mundo conectado. }\end{array}$ \\
\hline $\begin{array}{l}\text { Demonstrar como ferramentas digitais podem melhorar práticas pedagógicas e a qualidade da } \\
\text { aprendizagem. }\end{array}$ \\
\hline $\begin{array}{l}\text { Planejar processos de aprendizagem em ambientes autênticos de aprendizagem utilizando } \\
\text { aprendizagem móvel, mídia social e outras ferramentas online. }\end{array}$ \\
\hline Currículo baseado em competência e cooperação com empresas \\
\hline Descrever o que é currículo baseado em competência \\
\hline Analisar e planejar o alinhamento de objetivos de aprendizagem, avaliação, ambiente de apreı \\
\hline
\end{tabular}


Inovação curricular: contribuições finlandesas para estruturação de programas brasileiros de formação continuada de professores. Revista Ensaios, vol. 15, jul-dez de 2019.

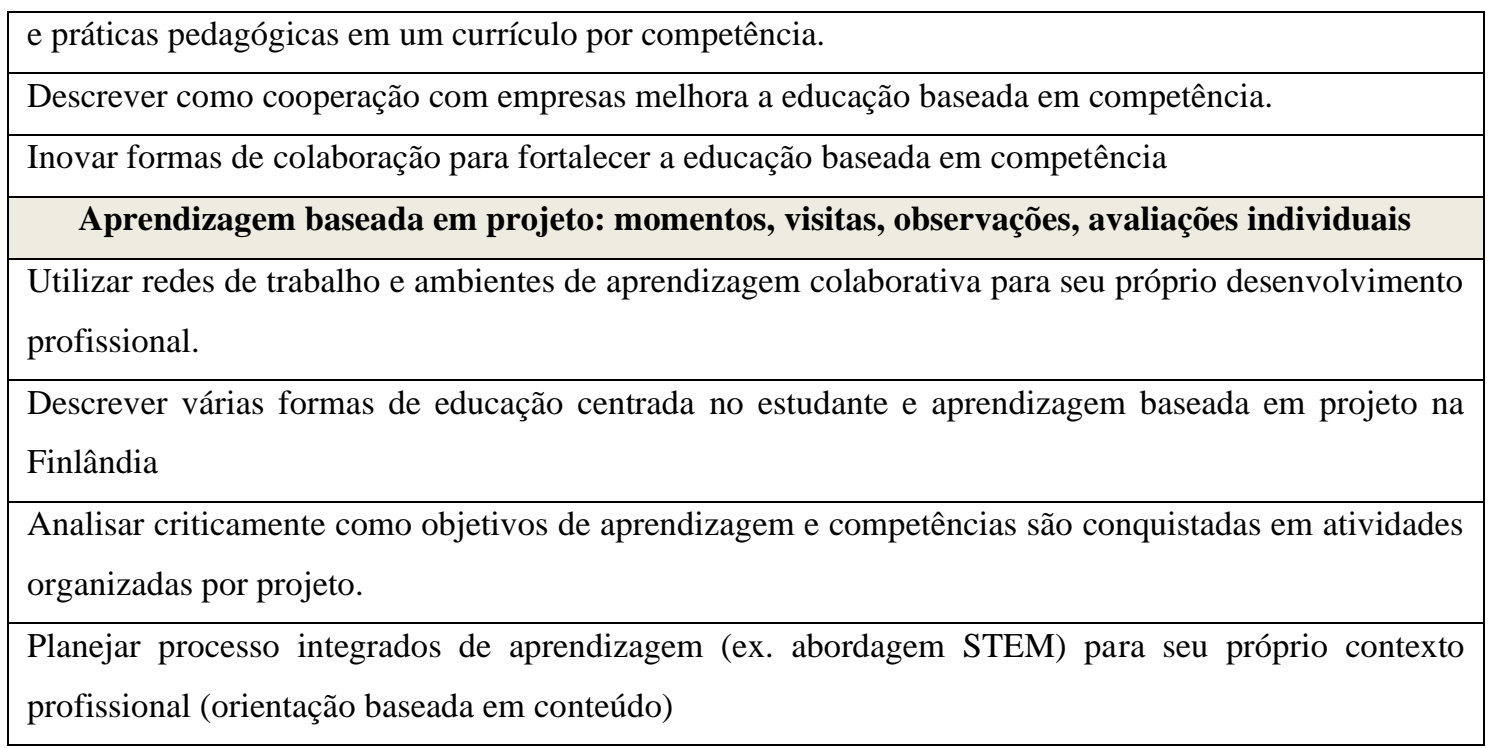

Como parte das atividades na Finlândia os participantes foram orientados a criar um plano de desenvolvimento para ser implementado em suas atividades docentes no Brasil. Para esta fase, o currículo do VET previa que os professores fossem capazes de:

- Formar grupo de desenvolvimento com base em interesses para colaboração no Brasil;

- Criar plano de trabalho;

- Apresentar o trabalho desenvolvido no Brasil;

- Compartilhar e apoiar o desenvolvimento do grupo;

- Analisar as necessidades de desenvolvimento, a implementação e os resultados do trabalho do grupo, de forma colaborativa;

- Apresentar o progresso do trabalho em sessões de orientação online;

- Apresentar os resultados e análises em grupo no seminário final.

Como dito, após três meses de formação na Finlândia, os participantes do programa VET III voltaram para suas atividades no Brasil e durante quatro (4) meses implementaram o plano de trabalho sob a orientação de Educadores finlandeses. 
Inovação curricular: contribuições finlandesas para estruturação de programas brasileiros de formação continuada de professores. Revista Ensaios, vol. 15, jul-dez de 2019.

Foi neste contexto que surgiu a proposta de criação de um curso de formação continuada para professores, inspirado no panorama do currículo real e formal do VET III Professores para o Futuro.

Passamos a apresentar o MAES sempre com a certeza de que ao produzir o texto estaremos nos desafiando a observar a criação como quem procura reconhecer e se reconhecer na e pela teia discursiva construída.

\section{4) O programa MAES: a escalada de um "monte de incertezas".}

"Você é prisioneiro do caminho que segue, somente a neve inexplorada é livre" Aaro Hellaakoski

Iniciamos a apresentação do Programa de formação continuada MAES Metodologias Ativas de Aprendizagem para o Estudante do Século XXI referenciando o Poeta Finlandês Aaro Hellaakoski com a afirmação de que "somos prisioneiros do caminho que seguimos, somente a neve inexplorada é livre" (tradução nossa). Ao trazer as palavras do poeta à nossa realidade constatamos que ao nos desafiar a promover melhorias em nossa prática como educadores vinculados à Rede Federal de Educação Profissional, Científica e Tecnológica (RFEPCT) brasileira, a única certeza que tínhamos era de que não teríamos neve a explorar no Brasil, no entanto, montes, montanhas e serras inexploradas encontraríamos em abundância.

Com esse entendimento, construímos o currículo do curso de extensão MAES, a partir da percepção de que com ou sem neve, caminhar era preciso. Assim, nos propusemos a escalar "um monte" de incertezas em colaboração com colegas participantes do Programa VET III Teacher for the Future. Como ponto de partida, constituímos uma rede colaborativa composta por professores de Institutos Federais de diferentes regiões do Brasil: IFB, Brasília (DF); IFRO, Porto Velho (RO); IFES, Vitória (ES); IFMS, Nova Andradina (MS). A rede foi organizada com base no conceito de Comunidade de Aprendizagem Profissional (Professional Learning Community, em inglês), cujo objetivo é a “criação e fortalecimento de uma comunidade docente

\footnotetext{
${ }^{4}$ Tradução dos autores
} 
Inovação curricular: contribuições finlandesas para estruturação de programas brasileiros de formação continuada de professores. Revista Ensaios, vol. 15, jul-dez de 2019.

constituída de importantes elementos que compõem a sustentabilidade, tais como colaboração, foco na aprendizagem, integração e liderança compartilhada. (CHEDIAK et al, 2018, p. 306-307).

Com o conhecimento adquirido na Finlândia, fruto da participação no Programa VET III Teachers for the Future, somado às experiências dos professores idealizadores do curso MAES, foi possível repensar a formação de professores em nosso contexto de atuação e desenhar o currículo do MAES, a partir dos pressupostos teóricos apreendidos e da realidade local de implementação do curso. Além disso, permitiu a percepção de que o espaço do saber, a escola, é também espaço de poder e de identidades, conforme defende Silva (2017).

Silva (2017) apresenta um mapa dos estudos sobre currículo em diferentes momentos da história, desde o currículo tradicional ou acrítica, currículo crítico e póscrítica. O currículo tradicional é um documento com especificações precisas de objetivos, procedimentos e estratégias para obtenção de resultados possíveis de mensuração, tendo como modelo a fábrica (BOBBIT, 1928 apud SILVA, 2017). A crítica ao currículo tradicional surge nas décadas de 70 e 80 do século XX. Autores como Louis Althusser (1918-1990) e Paulo Freire (1921-1997) surgem para apresentar a escola como espaço de reprodução de poder e aparelho ideológico do estado, transmissora de ideologia representada no currículo. A noção de currículo pós-crítico traz para debate questões como subjetividade e identidade. O olhar volta-se para o sujeito como único e diferente, refuta-se certezas absolutas e ideias fixas como verdades incontestáveis. O currículo é visto como espaço de poder, cujos porquês são fortemente discutidos.

Com esse entendimento, ao desenhar o currículo do MAES, buscamos construir conhecimentos a partir do que nos foi apresentado e do que compreendemos como currículo, tendo como orientação o pressuposto de Silva $(2017$, p. 146) de que "a ciência e o conhecimento, longe de serem o outro do poder, são também campos de luta em torno da verdade". Ou seja, temos consciência de que o paradigma educacional e o modelo de currículo que buscamos superar, provocaria novos saberes envoltos por relações de poder e constituições de identidades. 
Inovação curricular: contribuições finlandesas para estruturação de programas brasileiros de formação continuada de professores. Revista Ensaios, vol. 15, jul-dez de 2019.

Na sequência, apresentamos o caminho construído por quarenta e cinco (45) educadores brasileiros em constante diálogo com o espaço de contínua tensão e disputa (FOUCAULT, 2005) que se constituiu durante a implementação do curso MAES Metodologias Ativas de Aprendizagem para o Estudante do Século XXI.

\section{5) O MAES: a descoberta a partir da criação.}

O currículo do curso MAES foi desenhado com base nos princípios da Educação por competência, conforme apresentado pelos educadores finlandeses durante o desenvolvimento do Programa VET III, em 2016. Inicialmente, planejamos as competências gerais consideradas importantes para a formação de professores a partir dos pressupostos metodológicos da Aprendizagem Baseada em Projetos (ABP), no intuito de formar professores capazes de atender e entender o estudante brasileiro atual.

Durante o curso buscamos desenvolver nos professores as competências de: a) perceber o espaço escolar como ambiente de contradição e conflito; b) construir e desenvolver plano pedagógico de intervenção, buscando superar a prática educativa centrada no professor, à luz do paradigma da aprendizagem ativa; c) desenvolver habilidades de autoconhecimento, autogestão, empatia, responsabilidade, honestidade, afetividade e cooperação.

O recorte dos saberes apreendidos foi guiado pelos pressupostos de Baartman et al. (2017) que define competência como a integração de conhecimentos, habilidades e atitudes para gerenciar situações emergentes nas relações sociais, que a nosso ver, dialoga com o que é estabelecido pela Organização para a Cooperação e Desenvolvimento Econômico (OECD, 2016, p. 2) em que competência é "a capacidade de mobilizar conhecimento, aptidões, atitudes e valores, incluindo uma abordagem reflexiva dos processos de aprendizagem, de modo a envolver-se e atuar no mundo" e encontra respaldo no relatório entregue à UNESCO pela comissão presidida por Delors (2003), onde são apresentados os quatro (4) pilares para a Educação do século XXI: aprender a Conhecer, aprender a Fazer, aprender a Conviver e aprender a Ser. 
Inovação curricular: contribuições finlandesas para estruturação de programas brasileiros de formação continuada de professores. Revista Ensaios, vol. 15, jul-dez de 2019.

Como base para o desenvolvimento das estratégias metodológicas, o currículo do MAES foi estruturado em torno de cinco (5) competências: 1) utilizar ferramentas digitais para aprendizagem; 2) construir currículo integrado; 3) aplicar diferentes métodos de avaliação focados no desenvolvimento pessoal e profissional; 4) utilizar diferentes métodos colaborativos de ensino-aprendizagem; 5) desenvolver atitude de respeito, solidariedade, afetividade, responsabilidade e honestidade. Para cada competência, foram construídos objetivos de aprendizagem que contemplassem o saber conhecer, saber fazer, saber conviver e saber ser, conforme proposta de Delors (2003) para a educação do século XXI, a saber:

Quadro 2: Competências e objetivos de aprendizagem MAES. Fonte: os autores.

\begin{tabular}{|c|}
\hline Utilizar ferramentas digitais para aprendizagem \\
\hline Produzir e-portfolios; \\
\hline Realizar trabalho colaborativo com o suporte de mídias digitais; \\
\hline Utilizar ferramentas digitais para aprendizagem; \\
\hline Utilizar mídias sociais e outras ferramentas colaborativas; \\
\hline Desenhar processos de aprendizagem em ambientes de aprendizagem online; \\
\hline Integrar tecnologias digitais a partir dos princípios de educação híbrida e da sala de aula invertida; \\
\hline Influenciar colegas no processo de aprendizagem colaborativa; \\
\hline Construir currículo integrado \\
\hline Entender e descrever os princípios norteadores da Educação Baseada em Competência; \\
\hline Identificar pontos positivos e possibilidades de integração de conteúdos disciplinares; \\
\hline Apresentar e justificar as finalidades e desafios da Educação Baseada em Competência; \\
\hline Analisar currículos formais e propor integração de conteúdos curriculares; \\
\hline Transformar conteúdos em habilidades e competências; \\
\hline Planejar currículo integrado por competência; \\
\hline Implementar currículo integrado baseado em competências. \\
\hline Aplicar diferentes métodos de avaliação focados no desenvolvimento pessoal e profissional \\
\hline Identificar e descrever as concepções, objetivos e possibilidades de avaliação; \\
\hline
\end{tabular}


Inovação curricular: contribuições finlandesas para estruturação de programas brasileiros de formação continuada de professores. Revista Ensaios, vol. 15, jul-dez de 2019.

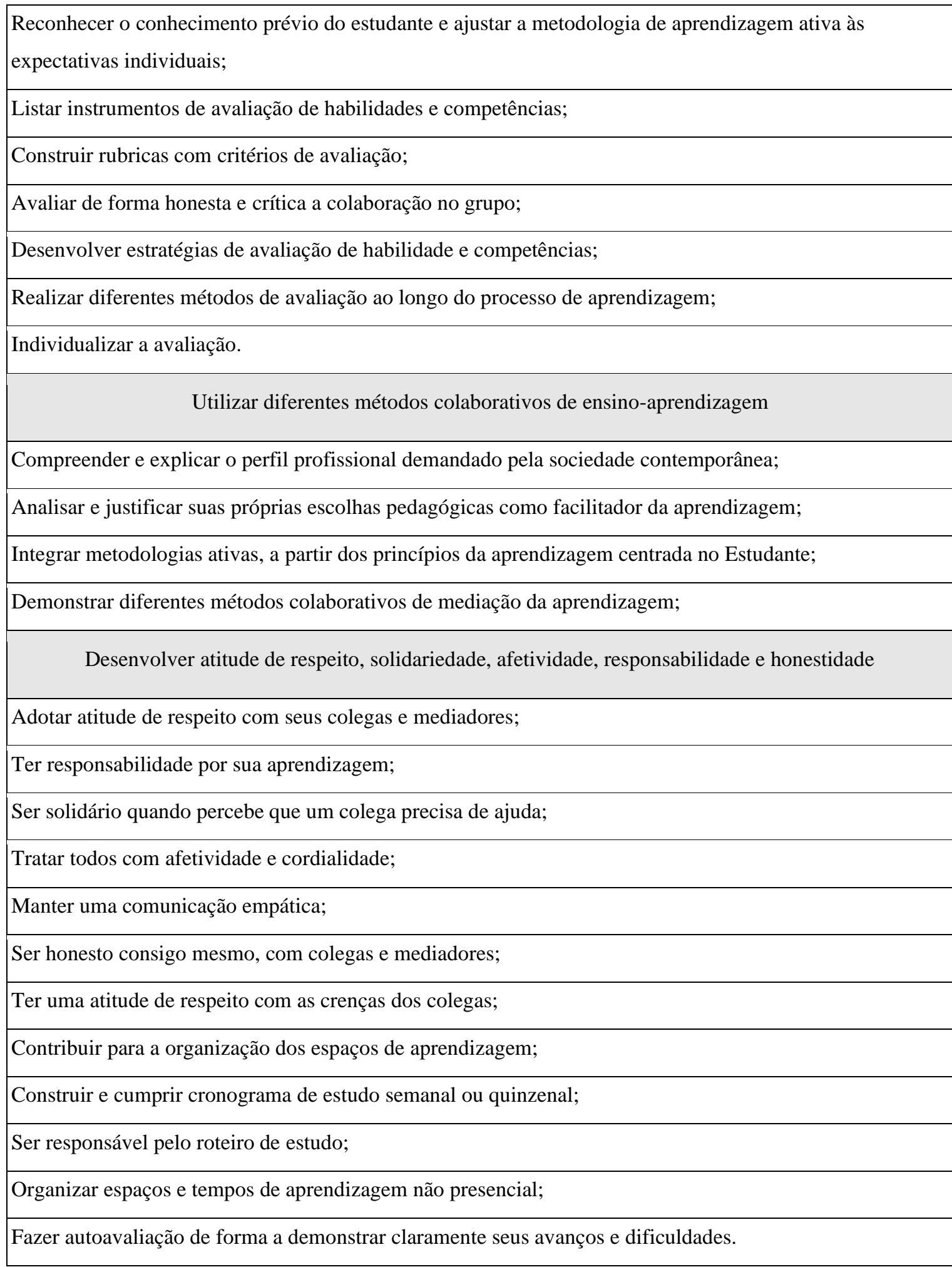

Definidas as competências e os resultados pretendidos, optamos pela metodologia de aprendizagem baseada em problemas e projetos (ABP) uma vez que compreendemos que a "ABP aumenta a motivação para aprender, trabalhar em equipe e 
Inovação curricular: contribuições finlandesas para estruturação de programas brasileiros de formação continuada de professores. Revista Ensaios, vol. 15, jul-dez de 2019.

desenvolver habilidades colaborativas" (BENDER, 2014, p. 16) além de ser "recomendada como uma técnica de ensino do século XXI", conforme enfatiza o autor.

Com base no princípio metodológico da ABP, delineamos os objetivos de aprendizagem, que nada mais é do que os resultados almejados, e as rubricas para que os participantes pudessem compreender e acompanhar os percursos previstos a serem construído ao longo do Curso MAES. Para Bender (2014, p. 20) "as rubricas são frequentemente usadas para proporcionar alguma estrutura para a experiência de ensino na $\mathrm{ABP}$, assim como para avaliar vários artefatos em sala de aula”. Segue, no Quadro 3, exemplos de algumas rubricas do Programa MAES:

Quadro 3: Rubrica para avaliação do Programa MAES. Fonte: os autores.

\begin{tabular}{|c|c|c|c|}
\hline Objetivo declarado & Suficiente & Bom & Excelente \\
\hline $\begin{array}{l}\text { Entender e descrever os } \\
\text { princípios norteadores do } \\
\text { Currículo Baseado em } \\
\text { Competência-CBC }\end{array}$ & $\begin{array}{l}\text { Resume de forma clara } \\
\text { e objetiva os princípios } \\
\text { norteadores do CBC }\end{array}$ & $\begin{array}{l}\text { Resume de forma clara } \\
\text { e objetiva os princípios } \\
\text { norteadores do CBC } \\
\text { e compara com } \\
\text { currículos tradicionais }\end{array}$ & $\begin{array}{l}\text { Resume de forma clara e } \\
\text { objetiva os princípios } \\
\text { norteadores do CBC, compara } \\
\text { com currículos tradicionais e } \\
\text { apresenta sugestões de } \\
\text { mudanças na prática; }\end{array}$ \\
\hline $\begin{array}{l}\text { Identificar e descrever as } \\
\text { concepções, objetivos e } \\
\text { possibilidades de } \\
\text { avaliação; }\end{array}$ & $\begin{array}{l}\text { Compara os tipos de } \\
\text { avaliação; }\end{array}$ & $\begin{array}{l}\text { Compara e justifica os } \\
\text { tipos de avaliação } \\
\text { adotados em sua } \\
\text { prática }\end{array}$ & $\begin{array}{l}\text { Compara, justifica os tipos de } \\
\text { avaliação adotados em sua } \\
\text { prática e avalia o tipo de } \\
\text { avaliação que melhor } \\
\text { contempla os princípios da } \\
\text { aprendizagem } \\
\text { ativa; }\end{array}$ \\
\hline
\end{tabular}

Esclarecemos que a rubrica não foi o único instrumento de orientação da aprendizagem e avaliação ao longo do curso. Ao encontro do que defende Bender (2014, p. 21), criamos uma variedade de práticas de ensino alinhadas à avaliação e ao ambiente de aprendizagem, à luz dos objetivos de aprendizagem propostos (BIGGS, 2003). 
Inovação curricular: contribuições finlandesas para estruturação de programas brasileiros de formação continuada de professores. Revista Ensaios, vol. 15, jul-dez de 2019.

O MAES teve uma duração de oito (8) meses, de abril a novembro de 2017. Configurou-se em três (3) fases complementares. A primeira fase consistiu-se de momentos presenciais e online em que os cursistas eram desafiados a solucionar problemas do cotidiano escolar relacionados à metodologia, avaliação, ambientes de aprendizagem e currículo. Na segunda fase, os professores cursistas foram orientados a construir planos pedagógicos que interviessem, de certa forma, na prática escolar e que colocassem os estudantes no centro do processo de ensino e aprendizagem. A terceira e última fase do curso consistiu no desenvolvimento do plano na escola, compartilhamento de experiências, reflexões teóricas e visitas técnicas.

O MAES contou com períodos de imersão em contextos escolares que apresentavam formas diferenciadas de organização curricular em comparação com os currículos da maioria das escolas brasileiras. Durante o curso foram organizadas duas (2) viagens de visita técnica. A primeira visita aconteceu em julho de 2017 à escola Projeto Âncora, localizada em Cotia, São Paulo. Participaram da visita, aproximadamente, cinquenta (50) Professores que se encontravam vinculados a programas de formação de professores no Instituto Federal de Mato Grosso do Sul IFMS, campus Nova Andradina, sendo estudantes do Programa MAES e do curso de pós-graduação (lato sensu) em Docência para a Educação Profissional, Científica e Tecnológica. A segunda visita aconteceu no período de 20 a 24 de novembro de 2017 em escolas de educação básica na Finlândia.

Na sequência apresentamos o currículo do Programa MAES representado na forma de uma árvore, fruto da descoberta de nossa criação (Figura 2): 
Inovação curricular: contribuições finlandesas para estruturação de programas brasileiros de formação continuada de professores. Revista Ensaios, vol. 15, jul-dez de 2019.

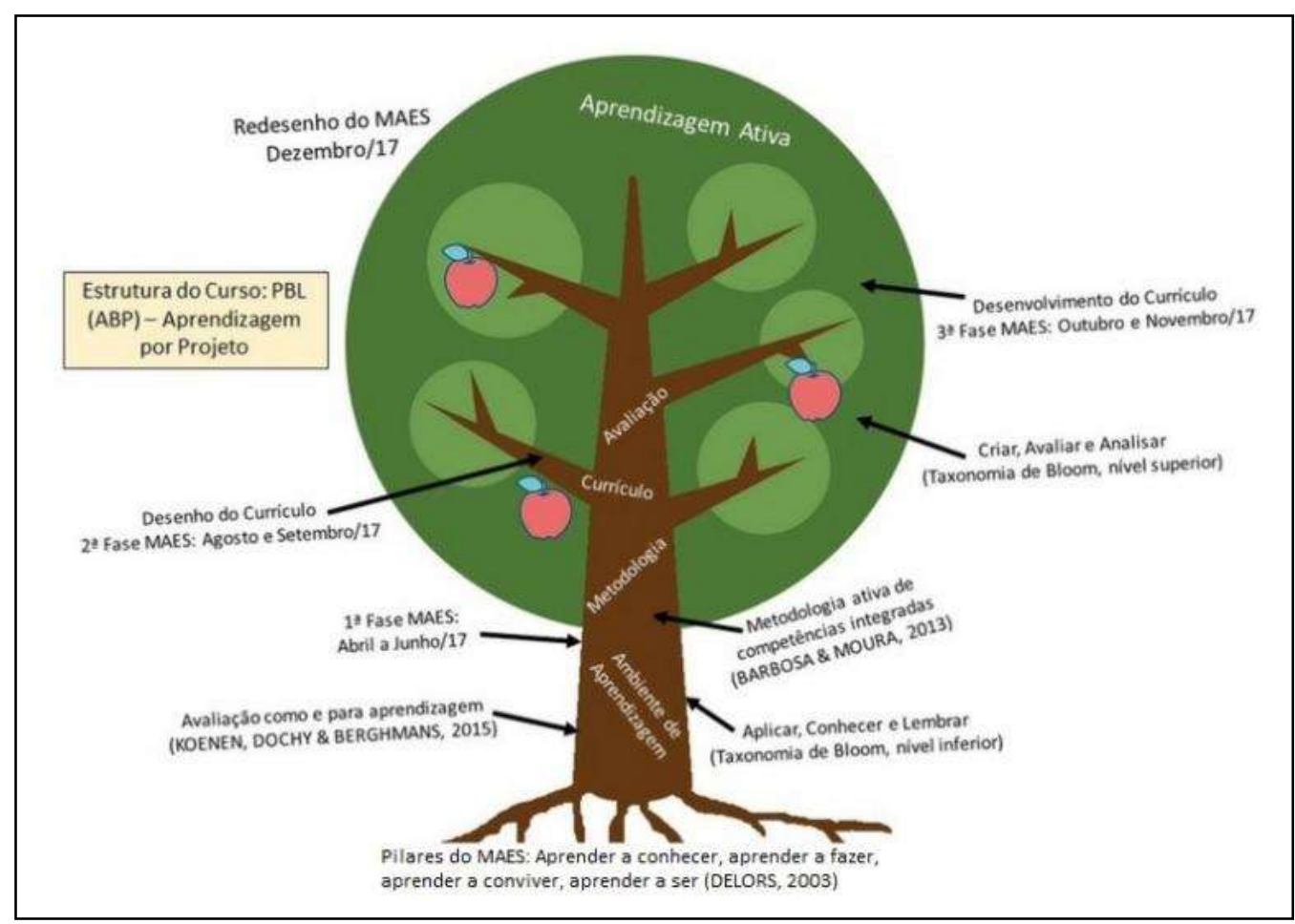

Figura 2: Representação do currículo do curso MAES. Fonte: os autores.

Com base nos pressupostos de Silva (2017) no que concerne às teorias de currículo, compreendemos que o currículo do MAES é "resultado de uma seleção", que por sua natureza ignora um universo infinito de conhecimentos e saberes para o constituir. Portanto, na dinâmica do percurso de sua construção dialógica o currículo do MAES é visto aqui como um espaço de luta em torno da verdade, tornando-se um documento de identidade, nossa identidade. Por outros termos, reconhecemos a produção do currículo do MAES como a representação de uma lógica que estabelecemos no percurso de busca pela construção de espaços educacionais que melhor atendessem às necessidades educacionais locais de nossa época. (SILVA, 2017).

\section{6) Análise e discussão: um olhar de cima do monte.}

Nesta seção, apresentamos e analisamos o que encontramos no topo do "monte de incertezas" dos Programas VET III e MAES. O momento é de refletir "o que nos revela o percurso", é de descobrir a criação. Tarefa complexa e subjetiva. De forma 
Inovação curricular: contribuições finlandesas para estruturação de programas brasileiros de formação continuada de professores. Revista Ensaios, vol. 15, jul-dez de 2019.

mais objetiva, no escopo dessa pesquisa analisamos como o programa MAES ressignifica o Programa VET III ao longo de sua constituição.

Ao "viajar" com e no comando do MAES percebemos as relações de poder, implicitamente, estabelecidas no espaço temporal e atemporal do curso. Conseguimos identificar os pontos de conflito causados pelo duelo estabelecido pelas múltiplas identidades emergentes no contexto de interação, provocadas pelos espelhos teóricos tradicional, crítico e pós-crítico de currículo (SILVA, 2017), refletidos por cada um dos participantes do curso.

Dizemos isso pois, assim como Silva (2017), entendemos teoria de currículo (e teoria em geral) como um "espelho" que reflete a realidade, capaz de explicar e justificar os caminhos trilhados por cada um. Sendo assim, ao tentar implementar o MAES, a partir do "modelo" de formação de professores VET III Teacher for the Future, as teorias (espelhos) em espaço de luta/conflito inventou-se um novo currículo, carregado de identidades daqueles que o constituiu. É, com base na percepção da criação de um novo currículo que iniciamos a apresentação e discussão dos aspectos ressignificados pelo Programa MAES tendo como principal âncora o Programa VET III.

Isso se dá tendo em vista que o currículo do Programa MAES foi organizado e estruturado com base nas nossas "formas" e "fôrmas" interpretativas (nos "espelhos") da realidade educacional vivida no Brasil e na Finlândia. Escolhemos o quê, por quê e como os professores deviam ser ou se tornar, qual o tipo de professor desejável à sociedade brasileira, a partir dos conceitos enraizados em nosso "eu" e em processo de reconstrução no caminho percorrido (FREIRE \& HORTON, 2003), que a nosso ver, dialogam em campos de conflitos e disputa de poder.

\section{7) Mudanças no MAES:}

Como observadores-participantes e confiantes de que "sem prática não há conhecimento", seguimos as orientações de Freire e Horton (2003) de que não há necessidade de ser especialista para se começar a caminhar, então simplesmente 
Inovação curricular: contribuições finlandesas para estruturação de programas brasileiros de formação continuada de professores. Revista Ensaios, vol. 15, jul-dez de 2019.

caminhamos, com o apoio de Professores e Estudantes de Nova Andradina, Professores de Institutos Federais de outras regiões do Brasil e Educadores Finlandeses.

Apoiados em lembranças e no princípio do diálogo como forma de interação e construção do/no caminho a percorrer, demos os primeiros passos e, sucessivamente, um passo de cada vez, durante os oito (8) meses de duração do curso MAES.

No exercício da caminhada, rumos foram corrigidos e ações alteradas de tal forma que a reflexão-sobre-a-ação do desenvolvimento dos programas nos permitiu perceber que o MAES ressignificou o VET III nos seguintes aspectos:

- Distribuição da carga horária

- Público-alvo atendido

- Competências e objetivos de aprendizagem

- Individualização

- Rubricas

- Integração curricular

Em relação à distribuição da carga horária, convém esclarecer que o Programa Finlandês de Formação de Professores VET III foi ofertado de forma concentrada e intensiva, ou seja, quarenta e dois (42) professores da Rede Federal de Educação Profissional, Científica e Tecnológica do Brasil afastaram-se de suas atividades institucionais no Brasil e durante três (3) meses se dedicaram, exclusivamente, às atividades do VET na Finlândia. Vinculados a uma universidade de Ciências Aplicadas - HAMK ou TAMK - as atividades de estudo dirigido foram intercaladas com visitas técnicas a escolas profissionalizantes. Ao retornar ao Brasil, durante quatro (4) meses (agosto a novembro/2016) os professores foram orientados a desenvolver ações de multiplicação dos conhecimentos construídos. O Programa VET III totalizou sete (7) meses de duração, enquanto o Programa MAES teve uma duração de oito (8) meses, com carga horária semanal de seis (6) horas de atividades presenciais. 
Inovação curricular: contribuições finlandesas para estruturação de programas brasileiros de formação continuada de professores. Revista Ensaios, vol. 15, jul-dez de 2019.

Percebe-se que o MAES criou uma dinâmica diferente de distribuição da carga horária do curso, o que permitiu que aspectos teóricos e práticos acontecessem paralelamente. Os cursistas eram constantemente incentivados a implementar na prática aspectos teóricos discutidos na interação com formadores e colegas de curso. Nesse ponto, buscamos fomentar a ação-reflexão-ação (SCHÖN, 2000), no intuito de atrelar teoria à prática escolar e aprender a caminhar caminhando (FREIRE \& HORTON, 2003).

Assim como o VET III, o MAES atendeu aproximadamente quarenta (40) professores. Todavia, não houve critério de seleção dos cursistas enquanto seu vínculo institucional, vindo a atender professores das redes Federal, Estadual, Municipal e Particular de Nova Andradina e região. Nesse ponto, o MAES se distanciou do VET, uma vez que o público alvo foi o professor em exercício, independe de seu contexto de atuação.

Outro aspecto ressignificado pelo MAES foi a base conceitual sobre competência. O trabalho educacional desenvolvido junto aos brasileiros pelos Educadores Finlandeses no programa VET III foi pautado nos princípios de que competência é a combinação do Saber, Fazer e Ser - Knowing, Doing, Being. No entanto, o MAES buscou embasamento em Delors (2003) e optou por seguir os pressupostos do: aprender a Conhecer, aprender a Fazer, aprender a Conviver e aprender a Ser. A inclusão do "aprender a Conviver" se justifica pela nossa percepção da pouca ênfase dada no dia a dia escolar a essa competência fundamental ao indivíduo contemporâneo. Diferentemente dos currículos escolares das escolas finlandesas, cuja estrutura escolar tem como base a promoção da colaboração, no Brasil percebe-se menor preocupação com esse aspecto, levando muitas vezes a não problematização de aspectos atitudinais na dinâmica e no convívio escolar, o que, a nosso ver, deve ser repensado, também, nos cursos de Formação de Professores.

A preocupação com o desenvolvimento de competências atitudinais, socioemocionais promoveu a ressignificação dos objetivos declarados no MAES que, diferentemente do VET, foram: a) perceber o espaço escolar como ambiente de contradição e conflito; b) construir e desenvolver plano pedagógico de intervenção à 
Inovação curricular: contribuições finlandesas para estruturação de programas brasileiros de formação continuada de professores. Revista Ensaios, vol. 15, jul-dez de 2019.

prática educativa centrada no estudante, à luz dos paradigmas educacionais contemporâneos; c) desenvolver habilidades de autoconhecimento, autogestão, empatia, responsabilidade, honestidade, afetividade e cooperação.

Por fim, o exercício de observar as trilhas e os rumos tomados, constatamos que apesar da adoção do mesmo pressuposto metodológico da Aprendizagem baseada em Projetos (ABP), doravante Project Based Learning (PBL) em inglês, adicionamos práticas pedagógicas não vividas no VET III, como a mentoria, a individualização, o uso de rubricas como critérios de avaliação dos resultados de aprendizagem e um maior enfoque à compreensão e construção de currículos apoiados nos princípios da Educação por Competência e a integração de áreas do conhecimento.

Os conceitos tácitos dos formadores somado ao constante pedido dos professores-cursistas para orientações "claras" do/no caminho que percorriam no/com o MAES fez com que o grupo de formadores locais, quatro (4) professores e dois (2) estudantes, organizassem grupos de whatsapp com cinco (5) ou seis (6) professorescursistas sob responsabilidade de um (1) formador, no intuito de manter a motivação, informar e esclarecer eventuais dúvidas. A esta prática denominamos de atividades de mentoria, algo que não aconteceu com tanta ênfase no Programa VET III.

Além disso, fruto da visita técnica à escola Projeto Âncora, construímos rubricas com critérios de avaliação e orientamos o registro de planos diários individuais de atividades, documento construído em planilha no GDrive, intitulada individualização $M A E S$, e a escrita de narrativas de aprendizagem. Os dois artefatos de avaliação formativa justificaram-se pela necessidade percebida no caminhar de instigar os professores-cursistas ao "hábito" de assumir a responsabilidade pela aprendizagem mediante autoavaliação constante do processo individual de aprendizagem. Na planilha, única para todos professores-cursistas, a cada encontro havia momentos de reflexão individual e planejamento de estudo.

Na segunda fase do MAES (agosto e setembro/2017) os professores-cursistas foram orientados na construção de planos de ensino-aprendizagem norteados por competências e objetivos de aprendizagem que integrassem diferentes áreas do conhecimento, levando em consideração os princípios apreendidos na primeira fase do 
Inovação curricular: contribuições finlandesas para estruturação de programas brasileiros de formação continuada de professores. Revista Ensaios, vol. 15, jul-dez de 2019.

curso (abril a junho/2017). O objetivo da ação foi fomentar a construção de currículos disciplinares, com conteúdos transformados em competências e a explicitação de objetivos integrados. Para esse processo/produto demos o nome de currículo integrado.

No que concerne às posturas metodológicas de mentoria, individualização e rubricas de avaliação, narrativas de aprendizagem, reconhecemos contradições entre nosso pensar e agir, explicitamente, na segunda e terceira fase do Curso MAES. Ao mesmo tempo que defendemos os princípios da confiança e um modelo educativo pautado na aprendizagem centrada no estudante, nos deparamos com construções de práticas pedagógicas influenciadas por posturas tradicionais que alimentam a ideia do controle do professor sob a ação do estudante, conceito vinculado ao paradigma de aprendizagem centrada no professor.

Nesse sentido, podemos enxergar "por detrás de nossas costas" (SILVA, 2017, p. 80), a invisibilidade das relações sociais que levaram à adoção de métodos de orientações individuais, quando na verdade, procurávamos implementar a colaboração entre os participantes. Enxergamos que a ênfase na mentoria e na adoção da planilha de individualização e rubricas como artefatos de avaliação são "atitudes, comportamentos, valores e orientações" (SILVA, 2017, p. 78) poderosos de controle e reforço ao individualismo no processo de aprendizagem. Silva (2017, p. 78) explica que "a situação de ensino fala mais do que o conteúdo explícito que se ensina", sendo assim, identificamos nas práticas elucidadas a criação de "dispositivos de controle" da aprendizagem do outro. Essa visibilidade de um aspecto, até então, invisível no currículo do MAES torna possível a mudança em práticas pedagógicas futuras.

\section{8) Considerações finais:}

É evidente para nós a teia conceitual envolta por contradições e tomadas de consciência no objeto em análise. O exercício de refletir sobre-a-ação nos ensina que a realidade se apresenta de diferentes formas àquele que busca interpretá-la. São, de fato, interpretações subjetivas e impregnadas de pré-conceitos, aceitos e refutados constantemente na dialética do aprender-fazendo. 
Inovação curricular: contribuições finlandesas para estruturação de programas brasileiros de formação continuada de professores. Revista Ensaios, vol. 15, jul-dez de 2019.

Conforme apresentado, descobrimos seis (6) aspectos ressignificados no MAES: distribuição da carga horária; público-alvo atendido; conceito e competências; enfoque metodológico em mentoria, individualização; rubricas; currículo integrado e por competência. No entanto, mantém-se encobertos muitos outros na tessitura do currículo "oculto", que o deixa de ser a partir de suas descobertas (SILVA, 2017).

Ao desenhar o MAES optamos por fazer a caminhada ao caminhar, desconfiamos de nossa neutralidade e atuação acabada. Seguimos o conselho de Aaro Hellaakoski, poeta finlandês, de nos tornar livres para explorar montes, morros, montanhas e todo caminho que desejávamos. Questionamos que tipo de homem tínhamos formado até então e que tipo de homem buscamos formar com o MAES. Exercitamos o "fazer com" em negação ao "fazer para". Aceitamos nossa condição de nos tornarmos especialistas na medida que nos constituímos na ação, com o propósito de trans-formar a nós mesmos para então sonhar pela trans-forma-ação da realidade educacional brasileira.

Partimos da premissa de que a educação não objetiva apenas fornecer pessoas qualificadas para servir ao mercado de trabalho. Seu potencial está em desenvolver o ser humano. Segundo Delors (2003, p. 5), “perante os múltiplos desafios suscitados pelo futuro, a educação surge como um trunfo indispensável para que a humanidade tenha a possibilidade de progredir na consolidação dos ideais da paz, da liberdade e da justiça social”. Essas premissas estão no relatório da UNESCO coordenado por Jacques Delors, que aponta quatro (4) pilares para Educação contemporânea, sendo: aprender a Conhecer, adquirir os instrumentos da compreensão e o desenvolvimento cognitivo; aprender a Fazer, para poder agir em ambientes complexos, aprender a Conviver, viver juntos a fim de participar e cooperar com os outros em todas as atividades humanas, e aprender a Ser, via essencial que integra os três pilares precedentes (DELORS, 2003).

Como dito, a participação como estudante nos programas de Formação de Professores VET III Professores para o Futuro (2016) promoveu percepções de currículo escolar, ainda ocultas ao nosso olhar. Percebemos que a "fôrma" curricular norteadora do tipo de ser humano formado pela Educação Brasileira é tradicional (MOREIRA \& TADEU, 2011), cuja perspectiva principal é o conhecimento cognitivo - 
Inovação curricular: contribuições finlandesas para estruturação de programas brasileiros de formação continuada de professores. Revista Ensaios, vol. 15, jul-dez de 2019.

saber Conhecer - com pouco, ou nenhuma ênfase no saber Fazer, saber Conviver e no saber Ser.

Essa percepção, entre outras, provocou inquietações e fomentou iniciativas em nosso contexto profissional no intuito de construir inovações em currículos de programas de formação de professores ofertados no Instituto Federal de Educação, Ciência e Tecnologia de Mato Grosso do Sul (IFMS). No entanto, temos consciência de que as reflexões e atividades desenvolvidas até o momento são incipientes. Há muito ainda a compreender, discutir e construir sobre o tema, o currículo.

Recebido em 25/11/2019. Aprovado em 12/05/2020. 
Inovação curricular: contribuições finlandesas para estruturação de programas brasileiros de formação continuada de professores. Revista Ensaios, vol. 15, jul-dez de 2019.

\section{Referências bibliográficas:}

BENDER, William N. Aprendizagem baseada em projetos: educação diferenciada para o século XXI. Tradução de Fernando de Siqueira Rodrigues. Porto Alegre: Penso, 2014.

BIGGS, John. Aligning teaching and assessment to curriculum objectives. Imaginative Curriculum Project, LTSN Generic Centre, 2003.

CHEDIAK, Sheylla. et al. Comunidades de Aprendizagem Profissional como estratégia de liderança na gestão escolar do século XXI. Revista Ibero-Americana de Estudos em Educação, Araraquara, v. 13, n. esp1, p. 304-323, maio 2018.

DELORS, Jacques. Educação: um tesouro a descobrir. 8. ed. São Paulo: Cortez, 2003.

FOUCAULT, Michel. Vigiar e Punir: nascimento da prisão. Petrópolis: Vozes, 2005.

FREITAS, Maria T. A. A abordagem sócio-histórica como orientadora da pesquisa qualitativa. Cadernos de Pesquisa, n. 116, p. 21-39, julho 2002. Disponível em: http://www.scielo.br/pdf/cp/n116/14397.pdf. Acesso em 18/06/2019.

HORTON, Myles et al. O caminho se faz caminhando: conversas sobre educação e mudança social. Tradução de Vera Lúcia Mello Josceline. Petrópolis, RJ: Vozes, 2003.

SCHÖN, Donald A. Educando o profissional reflexivo: um novo design para o ensino e a aprendizagem. Porto Alegre: Artmed, 2000.

SILVA, Tomaz T. Documentos de Identidade: uma introdução às teorias do currículo. 3. ed. Belo Horizonte: Autêntica, 2017.

VYGOTSKY, Lev S. A formação social da mente. São Paulo: Martins Fontes, 1984.

TYNJÄLÄ, Päivi; HÄKKINEN, Päivi; HÄMÄLÄINEN, Raija. TEL@ work: towards integration of theory and practice. British Journal of Educational Technology. v. 45, n. 6, p. 990-1000, 2014. 